\title{
Measure of rainfall time structure using the dimensionless $n$-index
}

\author{
Robert Monjo \\ Climate Research Foundation (FIC), C/ Gran Vía 22 (dupl.), 7º, 28013 Madrid, Spain
}

\begin{abstract}
The $n$-index is defined as the exponent of the power law relating the maximum average intensity over given periods of time (e.g. minutes, hours or days) and these periods of averaging. The $n$-index (between 0 and 1) reports on temporal variability of rainfall behaviour within an event. This study analyses the $n$-index around the world and its uncertainty according to several criteria of calculation and daily/sub-daily data. The results show that precipitation generally has a nested time structure, i.e. each maximum accumulation of shorter duration is included within a longer one, following a fractal behaviour. The obtained $n$-index is generally independent of the intensity and the event duration, but is sensitive to the temporal resolution of data. The distribution of the $n$-index around the world shows that areas with lower $n$ are the coldest regions and zones with marked orography. The highest $n$-index values are found near the warmest seas.
\end{abstract}

KEY WORDS: Rainfall time concentration $\cdot$ Sub-daily precipitation $\cdot n$-index $\cdot$ Convective precipitation $\cdot$ Fractal dimension

\section{INTRODUCTION}

Knowing the time structure of sub-daily precipitation is essential for hydrology, especially for the study of flash floods (Berne et al. 2009). Precipitation accumulation is relatively well measured by rain gauges, but instantaneous rain rate is very difficult to measure with high precision, even using pluviographs or disdrometers (Liu et al. 2013). Averaged intensities strongly depend on averaging time and rainfall time structure, which differs according to the natural processes that caused it. Thus, rainfall concentration over time is usually higher for storms than for events of stratiform rainfall.

Different techniques are available to describe the time structures of rainfall or its temporal concentration within an event. For example, the 'storm design' attempts to summarise characteristics of a heavy rain event for several time scales using the classical intensity-duration-frequency (IDF) relationship (Watt \& Marsalekb 2013). Synthetic hyetographs are desig-

*Corresponding author: rma@ficlima.org ned using mathematical functions such as power laws and beta functions (Koutsoyiannis 1993, D'Odorico 2005, Beven 2012). Some authors use methods of disaggregation and daily-to-sub-daily scaling based on a stochastic generation of sub-daily sequences. Examples are canonical/microcanonical cascades (Schertzer \& Lovejoy 1987, Gupta \& Waymire 1993), the Poisson process for storms (Koutsoyiannis et al. 2003, Cowpertwait et al. 2007) and the method of fragments (Mehrotra et al. 2012, Westra et al. 2012), which are based on the self-similarity shown by rainfall patterns at several time scales. According to fractal theory, precipitation behaviour can be described by a fractal dimension, obtained for example by the box-counting method or the Hurst exponent (Feder 1988, Olsson et al. 1992, Taouti \& Chettih 2014). Nevertheless, these methods find precipitation features, such as persistence, but do not offer an indication of rainfall concentration within a rain event.

On the other hand, several studies attempt to measure or classify precipitation according to its

() The author 2016. Open Access under Creative Commons by Attribution Licence. Use, distribution and reproduction are unrestricted. Authors and original publication must be credited. Publisher: Inter-Research · www.int-res.com 
daily concentration throughout the year. Some indices are based on Lorenz curves for rainfall, such as the Concentration Index (CI) of Martín-Vide (2004), which is climatically related to the percentage of days of rain that accumulate most of the annual precipitation (Cortesi et al. 2012, Benhamrouche et al. 2015). Similarly, Maraun et al. (2008) defined 10 sorted categories $\left(\mathrm{C}_{10}\right)$, and each one of them makes up $10 \%$ of the total rainfall amount for each month of the year. Klein-Tank \& Können (2003) analysed several indices, including the fraction of precipitation due to a set of wet days (95\% of wet days) for Europe.

Another way to study temporal concentration of rainfall is to focus on the convective/stratiform ratio. However, most indices that have been developed are based on specific thresholds obtained for a particular climatic region. An example of this is the $\beta$ index (Llasat 2001), designed for the Mediterranean region. The $\beta$ index of a rainfall event is defined as the fraction of cumulative rainfall with a 5 min intensity equal to or greater than $35 \mathrm{~mm} \mathrm{~h}^{-1}$, which was taken by Llasat \& Puigcerver (1997) as an indicator of convective precipitation. The IP index of Casas et al. (2010) can also be used to classify rainfall events according to the relationship between their intensities and durations (IDF curves). In particular, the IP index establishes variable thresholds according to the climate; it considers a return period of $5 \mathrm{yr}$ and durations of $5 \mathrm{~min}$ and 1, 2 and $24 \mathrm{~h}$.

In summary, all available rainfall indices attempt to characterise features such as the persistence (e.g. fractal duration), temporal concentration throughout the year ( $\mathrm{CI}$ and $\mathrm{C}_{10}$ ), or the convective/stratiform rainfall fraction according its relative intensity (IP and $\beta$ ). Meanwhile, rainfall time structure (within an event) is usually simulated using a stochastic generation but not using a simple index.

In this sense, one way to study the rainfall time structure is to examine the shape of IDF curves (fixing a particular frequency). The intensity-duration dependency can be expressed with a power law or a similar technique, as in the Chicago method and the alternating block method (Chow et al. 1988, Koutsoyiannis 1993, Ghahraman \& Hosseini 2005). The synthetic hyetograph computed by the Chicago method requires 2 parameters, but the power law method can be simplified by using 1 unique parameter. The fitted exponent of the power function is a dimensionless index that reports on the rainfall concentration over time, and therefore, gives an indication of the greater convective or advective contribution to the precipitation processes (Moncho et al. 2009). This shape index (henceforth, $n$-index) can be used not only for climate studies but also to analyse individual rain events, by applying it to empirical curves of maximum average intensities (Moncho et al. 2011). The $n$-index has been selected for this work because it has several advantages over the previous indices described: it does not depend on arbitrary thresholds, taking values from 0 to 1, and it can be applied to different time scales (sub-daily, daily or higher) both for climate statistics and studies of weather events. In fact, the $n$-index allows the extraction of sub-daily features of precipitation from daily data, thanks to the selfsimilarity of rainfall at several time scales. Hence, the aim of this work is to study the temporal behaviour of typical precipitation around the world, using the $n$-index.

\section{DATA}

For this study, a total of 66410 stations were chosen from the Global Historical Climatology Network-Daily database (GHCN-Daily), which contains over 85800 stations worldwide (Menne et al. 2012). The selected stations correspond to all of those with $\geq 1000$ values of precipitation and $\geq 70 \%$ temporal continuity. From the 66410 stations, slightly more than half had $>8000$ records, and over $75 \%$ had $>3000$ records with $98 \%$ continuity. About $25 \%$ of the stations stand out as having > 20000 daily records with $99 \%$ continuity. Daily data is very limiting for the analysis of most cases of convective events (sub-daily), but it can be used to study wet spells with high temporal irregularity. Other limitations of the data set are that it does not distinguish between solid and liquid precipitation, and there is no information on whether the gauges are heated for snowfall.

In order to improve the analyses, an additional dataset of 5347 sub-daily time series was collected from the Integrated Surface Hourly-Integrated Surface Data (ISH/ISD) of the National Climatic Data Centre (NCDC), which has >31700 stations worldwide (Smith et al. 2011). The selection was made on the basis of a length of at least 3000 values with $\geq 50 \%$ continuity over time (i.e. possible gaps divide time series such that the longest subset is $\geq 50 \%$ ) and with adequate quality (Dunn et al. 2012). In particular, a quality control was performed using the Kolmogorov-Smirnov test to detect inhomogeneities (Monjo et al. 2013). The most typical inhomogeneities resulted from constant and high values over several days (e.g. 999 for unavailable values), which were removed. Of the 5347 stations, $75 \%$ had 


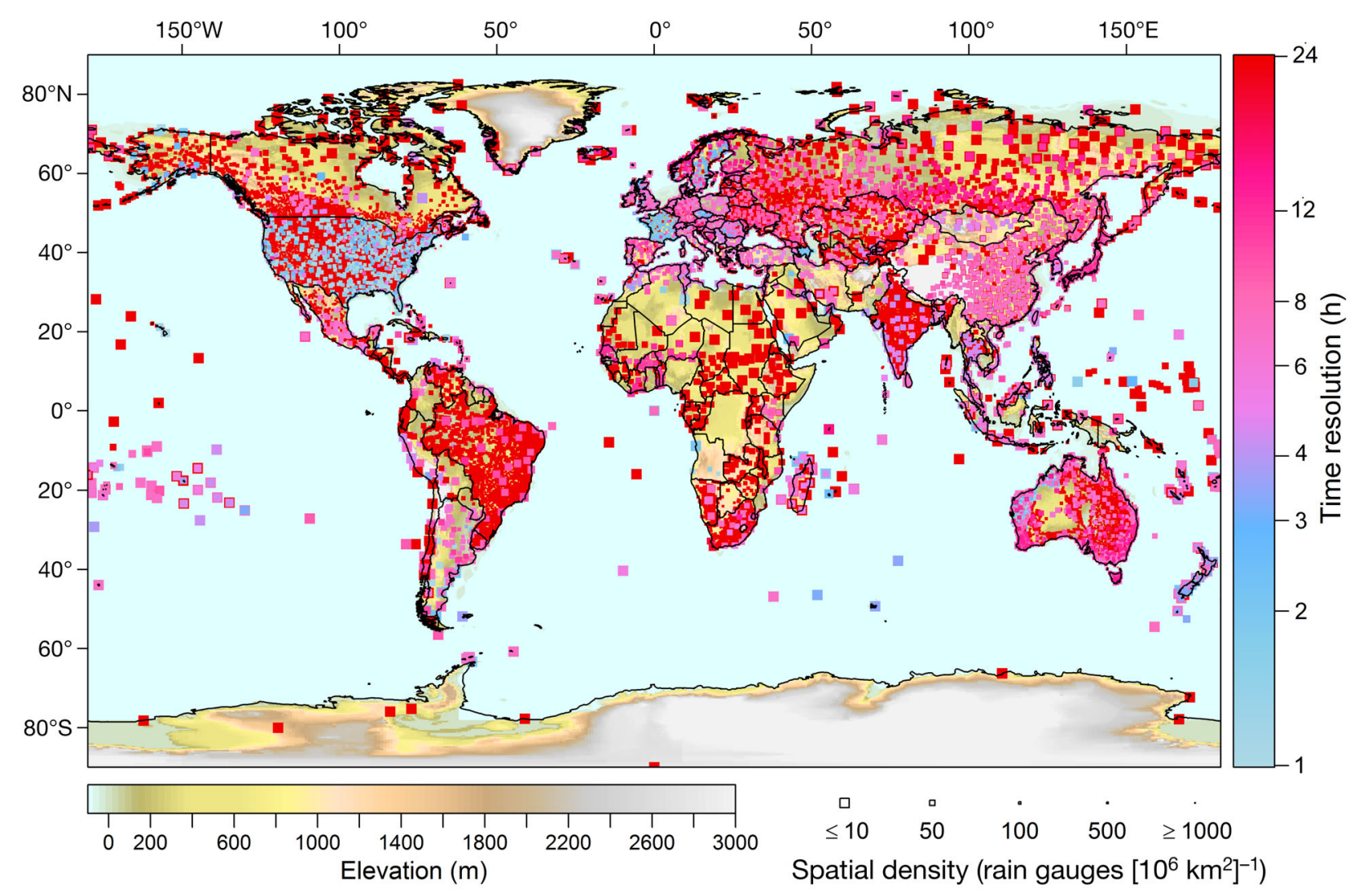

Fig. 1. Location of the rain gauges from the Global Historical Climatology Network-Daily database (red points) and from the Integrated Surface Hourly-Integrated Surface Data (other colours). The colour indicates the time resolution of the data (h). Point size is inversely proportional to the point density in each area

$>34000$ sub-daily records (in $5000 \mathrm{~d}$ ), and $50 \%$ had $>40000$ sub-daily records (in 10000 d) with $70 \%$ continuity. Regarding the temporal resolution of the subdaily data, only $17.8 \%$ have a reporting frequency of $1 \mathrm{~h}$. About $75 \%$ usually have a low reporting frequency ( 2,3 or 4 values per day). In particular, $42.2 \%$ have a $6 \mathrm{~h}$ frequency, $23.4 \%$ report every $12 \mathrm{~h}$ and $9.0 \%$ report 3 times per day. However, $45 \%$ of them sometimes report every 1 or $3 \mathrm{~h}$.

Combining both databases, a total of 69779 daily time series from the period 1950-2012 were available for this study. The spatial distribution is very uneven, depending on the country analysed (Fig. 1). This depends especially on its economic development or its former colonial dependence. Among the countries that have a higher density of stations are the USA, Brazil, India, Australia and the Netherlands. Africa has a low density in virtually all areas, except for the south. Polar and high altitude regions also have a low density of stations, due to their low population.

Precipitation events of $\geq 3$ consecutive wet days were analysed (see justification in Section 3.2). More than 25 million events at a daily scale and about
3 million at a sub-daily scale were studied. For comparative analysis between the scales, a common set of 2 million precipitation events was used.

\section{METHODOLOGY}

\subsection{Definition of the $n$-index}

Given a particular precipitation event, maximum amounts for several time intervals can be ordered according to the time interval length. If the maximum amounts are each divided by the time interval $(t)$, a curve of maximum average intensities (MAI) is obtained. In other words, a definition of the MAI as a function of time, $I(t)$, is given by:

$$
I(t) \equiv \frac{P(t)}{t}
$$

where $I(t)$ is the MAI of a time $t$, and $P(t)$ is the maximum accumulation in this time. Since maximum accumulations increase with time, $\mathrm{d} P(t) \geq 0$, and average intensities decrease with time, $\mathrm{d} I(t) \leq 0$, the simplest 
function $I(t)$ that satisfies these conditions is given by the following equation (see Appendix 1):

$$
I(t)=I\left(t_{o}\right)\left(\frac{t_{o}}{t}\right)^{n}
$$

where $I(t)$ and $I\left(t_{o}\right)$ are MAI, corresponding to times $t$ and $t_{o}$ and $n$ is a dimensionless parameter that is bounded between 0 and 1 . If time $t_{o}$ is fixed as a reference time (e.g. reporting time step), $I\left(t_{o}\right)$ is a fitted parameter, and thus, it is called the reference intensity. Parameters $I\left(t_{o}\right)$ and $n$ were fitted using non-linear minimisation of the mean squared error according to a Newton-type algorithm (Dennis \& Schnabel 1983). The Kolmogorov-Smirnov test was used to measure the goodness-of-fit. An example of fit is shown in Table 1 and Fig. 2.

Note that Eq. (2) is a power law, also used in some climate studies to characterise IDF curves (Ghahraman \& Hosseini 2005, Moncho et al. 2009). In the present study, the $n$ 'shape parameter' is used as an index that reports the time distribution of precipitation for observed events (no synthetic hyetographs). The original classification of rainfall according to the $n$-index has been revised here. Three classes are proposed to describe the average regime of rainfall time structure: regular $(n<0.5)$, efficient $(n=0.5)$ and irregular $(n>0.5)$. Regular rainfall is related to stationary
Table 1. (Left) A particular rainfall event of $8 \mathrm{~d}$ duration: individual reports $(p)$ in the first row; the table is a scheme to illustrate the method to obtain maximum accumulation for consecutive days (other rows). (Right) Maximum accumulation, $P(t)$, in $\mathrm{mm}$ for a time $t$ and its corresponding maximum average intensity, $I(t)$, in $\mathrm{mm} \mathrm{d}^{-1}$ (Fig. 2a). In this case, $I(t) \approx 5.6(1 / t)^{0.5}$, where the fitted value of the $n$-index is $n \approx 0.50 \pm 0.07$ (confidence interval of $95 \%$ )

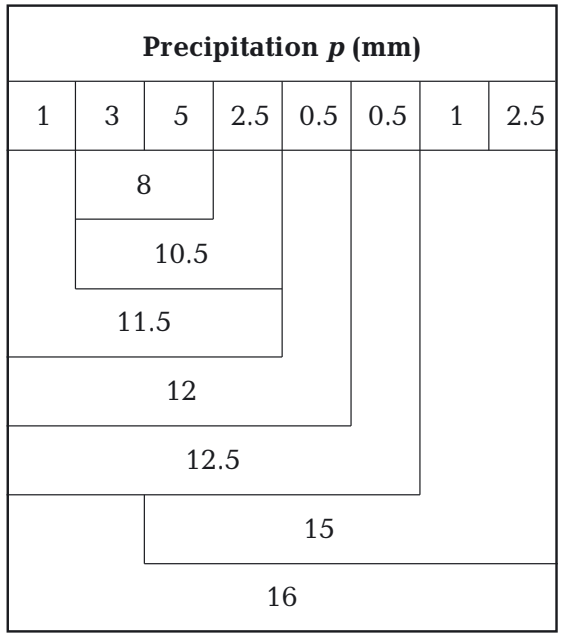

\begin{tabular}{ccc}
$\boldsymbol{t}$ & $\boldsymbol{P ( t )}$ & $\boldsymbol{I}(\boldsymbol{t})$ \\
\hline 1 & 5 & 5 \\
2 & 8 & 4 \\
3 & 10.5 & 3.5 \\
4 & 11.5 & 2.88 \\
5 & 12 & 2.4 \\
6 & 12.5 & 2.08 \\
7 & 15 & 2.14 \\
8 & 16 & 2
\end{tabular}

behaviour (e.g. orographic rainfall, static cell, etc.) while the predominance of irregular rainfall is associated with a rapid evolution (e.g. showers, thunderstorms, etc.). The 'efficient' value of 0.5 is related to the most extreme precipitation amounts (see Section 4.3).
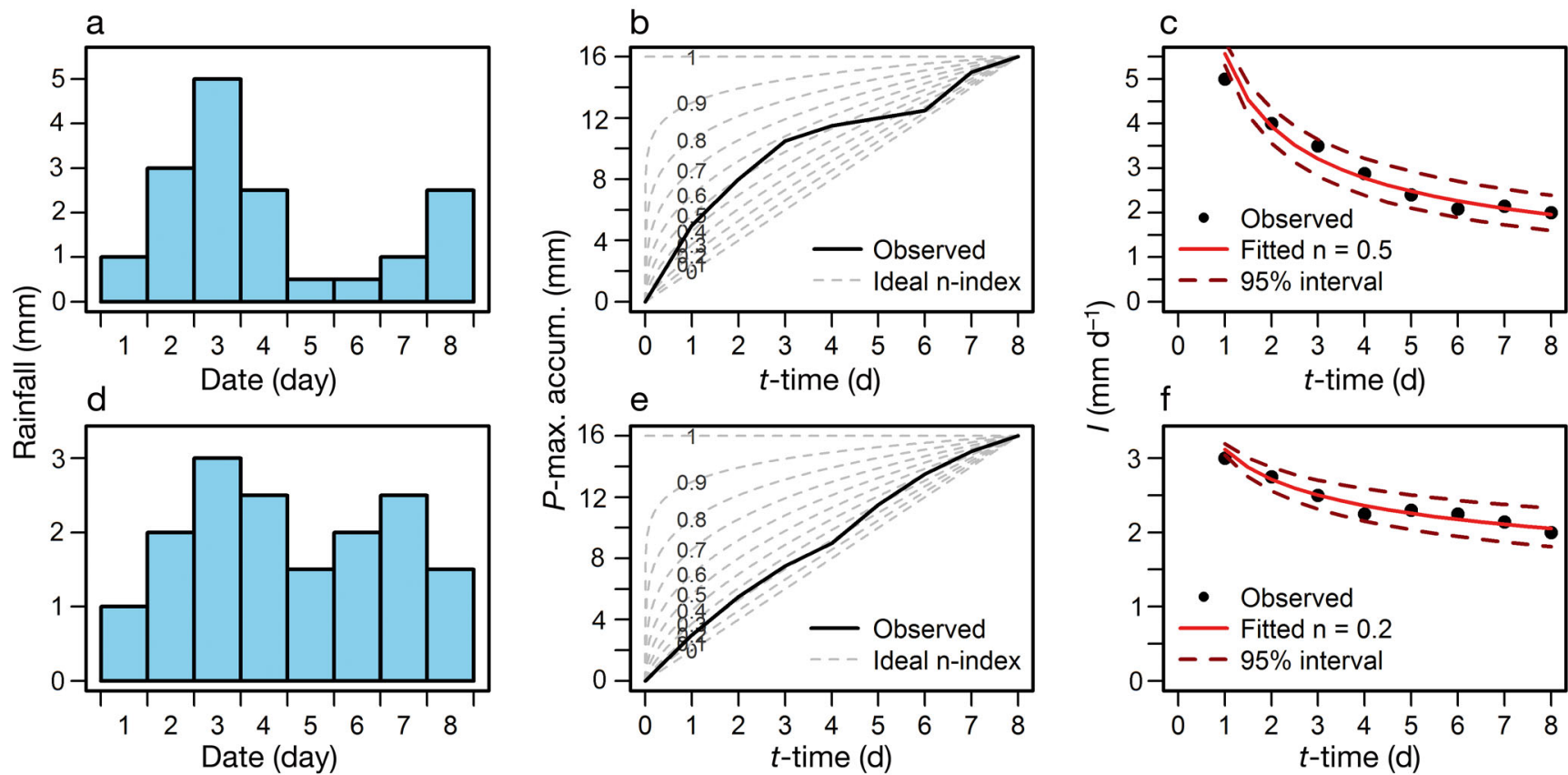

Fig. 2. Example of $n$-index estimation for 2 rainfall events from 8 individual reports: $(a, d)$ hyetographs; (b,e) maximum precipitation $P$ for the integration time $t_{i}(\mathrm{c}, \mathrm{f})$ maximum average intensities (MAI) $I$ and fitted curves for each case (Eq. 2). Theoretical curves (dashed lines) for maximum precipitation (b,e) are built from the combination of Eqs. (1) \& (2), i.e. $\mathrm{p}=P_{\max }\left(t / t_{\max }\right)^{1-n}$ 


\subsection{Fractal interpretation}

Rainfall self-similarity at several time scales was one of the inspirations for this study. For this reason, the main concepts of fractality were analysed for the rainfall in order to find a theoretical relationship with the $n$-index (see Appendix 2). In particular, the $n$ index can be understood as a fractal dimension of the rainfall intensity, because the intensity is a 'density' of rainfall over its duration, which has a fractal feature according to the box-counting analysis (Olsson et al. 1992, Taouti \& Chettih 2014). Therefore, it is expected that MAI $\left(I_{k}\right)$ depends on time resolution $r_{k}$ as:

$$
I_{k}\left(r_{k}\right)=I_{1}\left(r_{1}\right)\left(\frac{r_{1}}{r_{k}}\right)^{n_{F}}
$$

where $r_{1}$ is fixed (e.g. $\left.1 \mathrm{~d}\right), I_{1}\left(r_{1}\right)$ is a fitted constant, and $n_{F}$ is the $n$-index acting as fractal dimension of the MAI. In this equation, time resolution $r_{k}$ can be understood as an averaging time of the MAI. The fractal index $\left(n_{F}\right)$ has special interest for some uses (e.g. rainfall stochastic simulation) due to its relationship with the fractal dimension of the event duration (d), given by the inequality $d \leq n_{F} \leq 1$ (see details in Appendix 2).

To fit $n_{F}$, each rainfall event is regrouped into nonoverlapping segments (boxes) of resolution $r_{k}$, which is chosen as being proportional to $2^{k}$ times the initial temporal resolution $r_{0}$, that is $r_{k}=2{ }^{k} r_{0}$. A minimum of 3 values is considered for $k(0,1$ and 2$)$.

\subsection{Criteria and uncertainties}

Some uncertainties in the $n$-index were found, depending on the considerations taken into account for calculation. In particular, 3 different criteria were analysed: (1) MAI calculation method, (2) duration of the event, and (3) temporal resolution of data.

Considering these factors, several combinations of criteria can be examined. Six different $n$ were defined with 3 subscripts representing the 3 criteria (Table 2): $n_{\mathrm{As} \sigma}, n_{\mathrm{Ns} \sigma}, n_{\mathrm{Ax \sigma}}, n_{\mathrm{Nx} \sigma}, n_{\mathrm{As} \delta}, n_{\mathrm{Ns} \delta}$. Note that $n_{\mathrm{Ax} \delta}$ and $n_{\mathrm{Nx} \delta}$ are not listed here because the relaxed and strict durations are the same for the daily scale, unless the definition of relaxed is changed. A 'nested

Table 2. Three criteria to calculate the $n$-index, and examples of individual reports $(p)$, maximum amounts $(P)$ and maximum average intensity $(I)$ in arbitrary units and time resolution $r$. The value of $n$ is fitted for each example. MAI: maximum average intensity

\begin{tabular}{|c|c|c|c|c|}
\hline Criterion & Tyре & Symbol & Specification & Example \\
\hline 1 & Absolute & $\mathrm{A}$ & $\begin{array}{l}\text { No approach is considered. MAI is taken for each time interval } \\
\text { from the absolute maximum amount in each case. }\end{array}$ & $\begin{array}{c}p: 2,7,3,5,6 \\
P: 7,11,15,21,23 \\
I: 7,5.5,5,5.25,4.6 \\
\quad n_{\mathrm{A}}=0.21\end{array}$ \\
\hline 1 & Nested & $\mathrm{N}$ & $\begin{array}{l}\text { An approach considered to estimate MAI: contiguous-to-the- } \\
\text { maximum values are taken, sequentially from the highest to } \\
\text { the lowest rainfall record. }\end{array}$ & $\begin{array}{l}p: 2,7,3,5,6 \\
P: 7,10,12,17,23 \\
I: 7,5,4,4.25,4.6 \\
\quad n_{N}=0.19\end{array}$ \\
\hline 2 & Strict & $\mathrm{s}$ & $\begin{array}{l}\text { The duration of a rainfall event is delimited by } 2 \text { 'dry' reports } \\
\text { (initial and final). A report is considered 'dry' if there is }<0.1 \mathrm{~mm} \\
\text { precipitation. }\end{array}$ & $\begin{array}{c}p: 0,2,7,3,0,5,6,0 \\
P: 7,10,12 \\
I: 7,5,4 \\
n_{\mathrm{As}}=0.51\end{array}$ \\
\hline 2 & Relaxed & $\mathrm{x}$ & $\begin{array}{l}\text { The duration of the event is taken from the time interval } \\
\text { between } 2 \text { consecutive reports of }<0.1 \mathrm{~mm} \text { for } \geq 24 \mathrm{~h} \text {. } \\
\text { That is, a 'dry' pause of }<24 \mathrm{~h} \text { is allowed. }\end{array}$ & $\begin{array}{c}\text { If } r<1 \mathrm{~d} \\
p: 0,2,7,3,0,5,6,0 \\
P: 7,11,12,14,17 \\
I: 7,5.5,4,3.5,3.4 \\
n_{\mathrm{Ax}}=0.48\end{array}$ \\
\hline 3 & Sub-daily & $\sigma$ & $\begin{array}{l}\text { The time interval between one report and another is }<1 \mathrm{~d} \text {, } \\
\text { usually } 6,3 \text { or } 1 \mathrm{~h} \text {. }\end{array}$ & $\begin{array}{c}\text { For instance, } r=8 \mathrm{~h} \\
p: 0,2,7 ; 3,0,5 ; 6,0,0 \\
n_{\text {As }}=0.51 \\
n_{\text {Axo }}=0.48\end{array}$ \\
\hline 3 & Daily & $\delta$ & The time interval between one report and another is $1 \mathrm{~d}$. & $\begin{array}{c}\text { The previous case, } \\
\text { aggregated at } r=1 \mathrm{~d} \\
\quad p: 9,8,6 \\
n_{\mathrm{As} \delta}=n_{\mathrm{Ax} \delta}=0.17\end{array}$ \\
\hline
\end{tabular}


rainfall event' of duration $T$ occurs when all the maximum amounts accumulated in $t<T$ contain each other as a sub-event. For example, the rainfall event described in Table 1 is nested for the sub-event of the first to sixth days, but the seventh maximum accumulation does not contain this sub-event.

In order to test sensitivity to the criteria, comparisons were performed for several pairs of samples, each of 69779 averaged values of $n$ : comparing nested and absolute indexes, comparing strict and relaxed indexes, and comparing daily and sub-daily scales. In each case, the other 2 criteria were fixed. Therefore, 3 pairs of $n$ were considered for the first comparison: $n_{\mathrm{As} \sigma}$ with $n_{\mathrm{Ns} \sigma}, n_{\mathrm{Ax} \sigma}$ with $n_{\mathrm{Nx} \sigma}$, and $n_{\mathrm{As} \delta}$ with $n_{\mathrm{Ns} \delta}$. For the second comparison, 2 pairs were used: $n_{\mathrm{Ax \sigma}}$ with $n_{\mathrm{As} \sigma}$, and $n_{\mathrm{Nx \sigma}}$ with $n_{\mathrm{Ns} \sigma}$. For the third, the other 2 pairs were compared: $n_{\mathrm{Ax} \delta}$ with $n_{\mathrm{Ax} \sigma}$, and $n_{\mathrm{Nx} \delta}$ with $n_{\mathrm{Nx} \sigma}$.

According to the definition of the $n$-index, the fractal version $\left(n_{\mathrm{F}}\right)$ can give an indication of the selfsimilarity of the intensity at several time scales. Thus, the comparison between absolute and fractal indexes was used to characterise this aspect (Eq. 3).

To estimate the $n$-index in all cases it was necessary to use at least 3 consecutive wet values (i.e. precipitation $>0$ ), since the error of fit (Eq. 2) produced by using 2 unique values is too high. This is because a precipitation event shorter than 2 time steps can be placed symmetrically or asymmetrically between the 2 consecutive measurements, causing large differences in the estimation of $n$.

Therefore, to compare daily and sub-daily $n$ (e.g. $n_{\mathrm{Ax} \delta}$ and $n_{\mathrm{Ax} \sigma}$ ), it was necessary to use a duration of at least $3 \mathrm{~d}$ for both. For the same reason, to compare strict and relaxed $n$ (e.g. $n_{\mathrm{As} \sigma}$ and $n_{\mathrm{Ax \sigma}}$ ), an additional consideration is required for the strict $n$ : throughout the relaxed duration of the event, several strict sub- events of shorter strict duration occur. Thus, the strict $n$ considered (e.g. $n_{\text {As }}$ ) was the average $n$ of the main precipitation sub-events (upper half, classified by precipitation amount).

Statistical analysis of the data was preformed using R (Muenchen \& Hilbe 2010, R Development Core Team 2010). Pearson correlations of $n$ were computed using the $t$-test at the minimum significance level allowed for floating point numbers (i.e. $p$-value $<2 \times 10^{-16}$ ), due to the high number of values (from the 69779 rain gauges). Parameter errors expressed in parentheses (significant figure) are at the 95\% confidence level.

\section{RESULTS AND DISCUSSION}

\subsection{Comparing criteria for the calculation of $n$}

The estimated error rate (95\% confidence level) for fitted $n$-values was $18 \%$ on average, and was between 2\% (Q1) and 25\% (Q3) for all rainfall events. Most climatic averages of the $n$-index are close to 0.5 , i.e. in the middle of the bounds (0 and 1). However, significant differences were observed depending on the selected criteria, especially the second and third. Regarding the first criterion, the Pearson correlation coefficient between absolute and nested $n$ was very high ( $\mathrm{r}=0.998$ ) and was generally independent of data resolution (sub-daily/daily) and of event duration (strict/relaxed). For example, Fig. 3a shows a comparison of both MAI methods (absolute/nested) for strict duration at sub-daily scale $\left(n_{\mathrm{As} \sigma} \mathrm{vs} . n_{\mathrm{Ns} \sigma}\right)$, but all the other cases were similar. Differences between the absolute and nested $n$ were $<1 \%$. Fractal interpretation of the MAI led to a fractal version $\left(n_{\mathrm{F}}\right)$ that was highly correlated with the absolute/nested
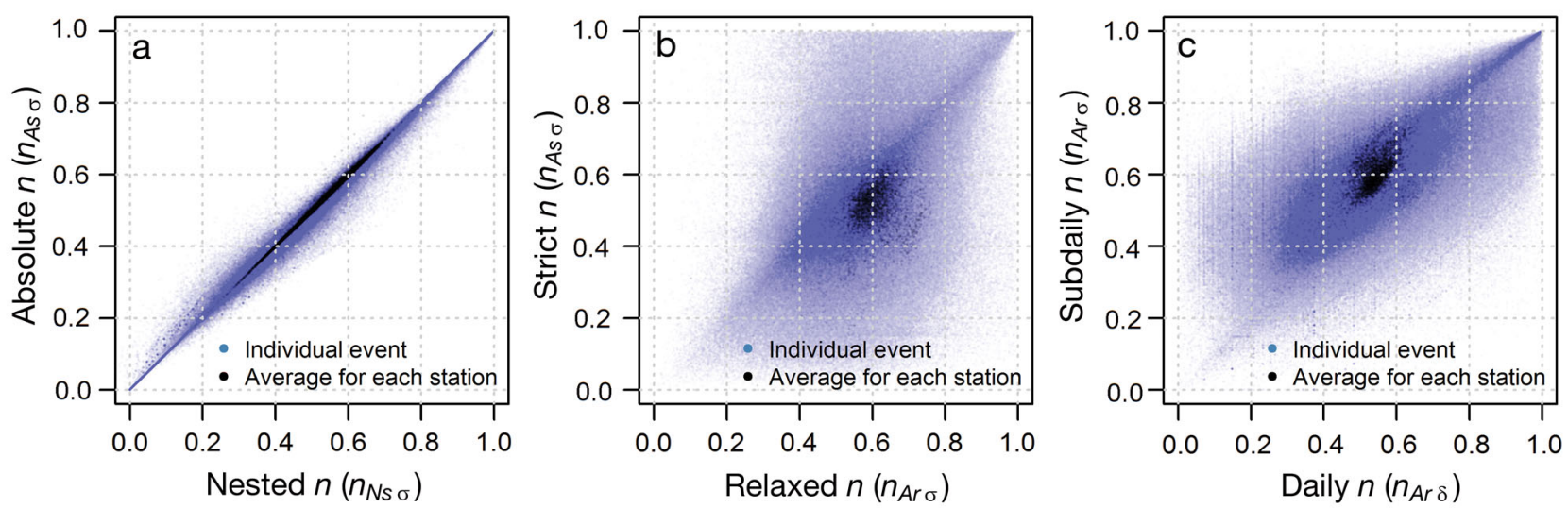

Fig. 3. (a) Comparison between nested and absolute $n$, for sub-daily cases. (b) Comparison between strict and relaxed subdaily $n$. (c) Comparison between daily and sub-daily $n$, for the same duration of at least $3 \mathrm{~d}$ 
version. A Pearson correlation coefficient of 0.90 was obtained in both cases. The mean difference between $n_{\mathrm{F}}$ and absolute/nested $n$ was about $+7 \%$; in fact, the slope was $1.070 \pm 0.004$.

According to the second criterion for $n$ estimation, important uncertainties were found due to differences between strict and relaxed durations of sub-daily events, which can be up to $50 \%$. A globular cluster with an ellipse form can be observed at the centre of the cloud of points (Fig. 3b). This cluster varies between approximately 0.3 and 0.8 for the relaxed $n$ domain, while it varies between 0.2 and 0.9 for the strict $n$ domain. That is, for events of at least 3 consecutive wet days, strict $n$ of main sub-events is more variable than the relaxed $n$. This was expected due to the smoothing effect forced by the increase in integration intervals for the relaxed cases.

For the third criterion (fixing the second criterion at the same duration), it should be noted that there were no records for $n<0.2$ for the relaxed sub-daily $n$; however, the abundance was higher for daily cases (Fig. 3c). Moreover, the centred cluster formed an ellipse lying slightly above the horizontal, which implies a lower variability of sub-daily $n$ than daily $n$. In this case, the Pearson correlation coefficient was only 0.68 , and the mean absolute difference was about $30 \%$.

\subsection{Rainfall time structure around the world}

Most of the studied cases from around the world showed an average $n$ between 0.45 and 0.60 , both on daily and sub-daily scale (i.e. $n_{\mathrm{As} \delta}$ and $n_{\mathrm{As} \sigma}$ ). Nevertheless, spatial distribution differed noticeably in the tropical/subtropical regions according to the time scale analysed (Fig. 4).

Regarding the regions with common outcomes for both time scales, some areas with high rainfall irregularity $(n>0.5)$ can be found: the Northern Gulf of Mexico, the African rainforest and savannah, some parts of South America, eastern China, Oceania and some areas of the Mediterranean basin. According to studies of global frequency and distribution of lightning, these areas are characterised by remarkable convection (Christian et al. 2003). On the other hand, the consensus areas with a (predominantly) regular regimen of precipitation $(n<0.5)$ are: northern Canada, northern Asia, polar areas, orographic effect areas (eastern Himalaya, west side of the Andes) and areas affected by the Indian monsoon.

The most important differences were in areas with irregularity at the daily scale and regularity at the sub-daily scale. For example, the western USA is affected by the cool California current and humid westerly winds, with which a regimen of predominantly stratiform precipitation is expected (Granger 2005). However, on a daily scale (3 or more days), the fronts move quickly, causing a rather irregular rainfall time structure. Something similar happens in South Africa, in parts of Australia, and to a lesser extent, also in northern Europe. Regarding the case of India, an effective combination of advective/ convective precipitation is caused by the summer monsoon (Singh \& Nakamura 2010, Jiangnan et al. 2014), and therefore, an intermediate irregularity $(n \approx 0.5)$ is expected in rainfall behaviour on the subdaily scale. However, a greater irregularity was observed on the daily scale, probably due to the daily effects of the high frequency of convective systems (Christian et al. 2003), in addition to the influence of daily movements of the planetary-scale tropical rain belt (Gadgil 2003).

In general terms, the sub-daily/daily ratio of $n$ (particularly $n_{\mathrm{As} \sigma} / n_{\mathrm{As} \delta}$ ) was between 0.8 and 1.1, with an average value of about 0.9. The regions characterised with irregular rainfall showed a quotient $\geq 1$, while regions with a regular rainfall regimen presented a quotient $<1$. This is due to daily $n$ having lower variability than sub-daily $n$, and can be approximated to $n_{\mathrm{As} \delta} \approx 0.54 \pm 0.06$, while $n_{\mathrm{As \sigma}} \approx 0.50 \pm 0.10$ (with $1 \mathrm{SD}$ ). In fact, the weak dependency is $n_{\mathrm{As} \delta} \approx$ $(0.403 \pm 0.005)+(0.263 \pm 0.009) \times n_{\text {As }}$ (significant figures at $95 \%$ confidence level).

The differences between $n_{\mathrm{As} \delta}$ and $n_{\mathrm{As} \sigma}$ can also be explained using the latitudinal profile of $n$ (Fig. $4 \mathrm{~b}, \mathrm{~d}$ ). The daily $n$ profile reflects the latitudes where ascents occur due to dynamic forcing - that is, around $40^{\circ}$ north and south, linked to the interactions between subtropical and polar-front jet streams, and a thin strip around the equator, corresponding to the centre of the Intertropical Convergence Zone (ITCZ) (Granger 2005). In these regions, a predominance of irregular precipitation $(n>0.5)$ was expected on a daily scale. On the other hand, the sub-daily $n$ profile showed an important dependence on location in the warmest regions of the planet (i.e. tropical and subtropical areas), although it has a greater uncertainty (due to fewer data points). Therefore, sub-daily $n$ is more representative than daily $n$ concerning the convective/stratiform fraction of precipitation, especially as it best represents latitudes with the highest frequency of convection (Christian et al. 2003). Convection processes are less reflected on the daily scale because large-scale processes (e.g. planetary waves) have an effect on the variability of $n$. Nonetheless, 


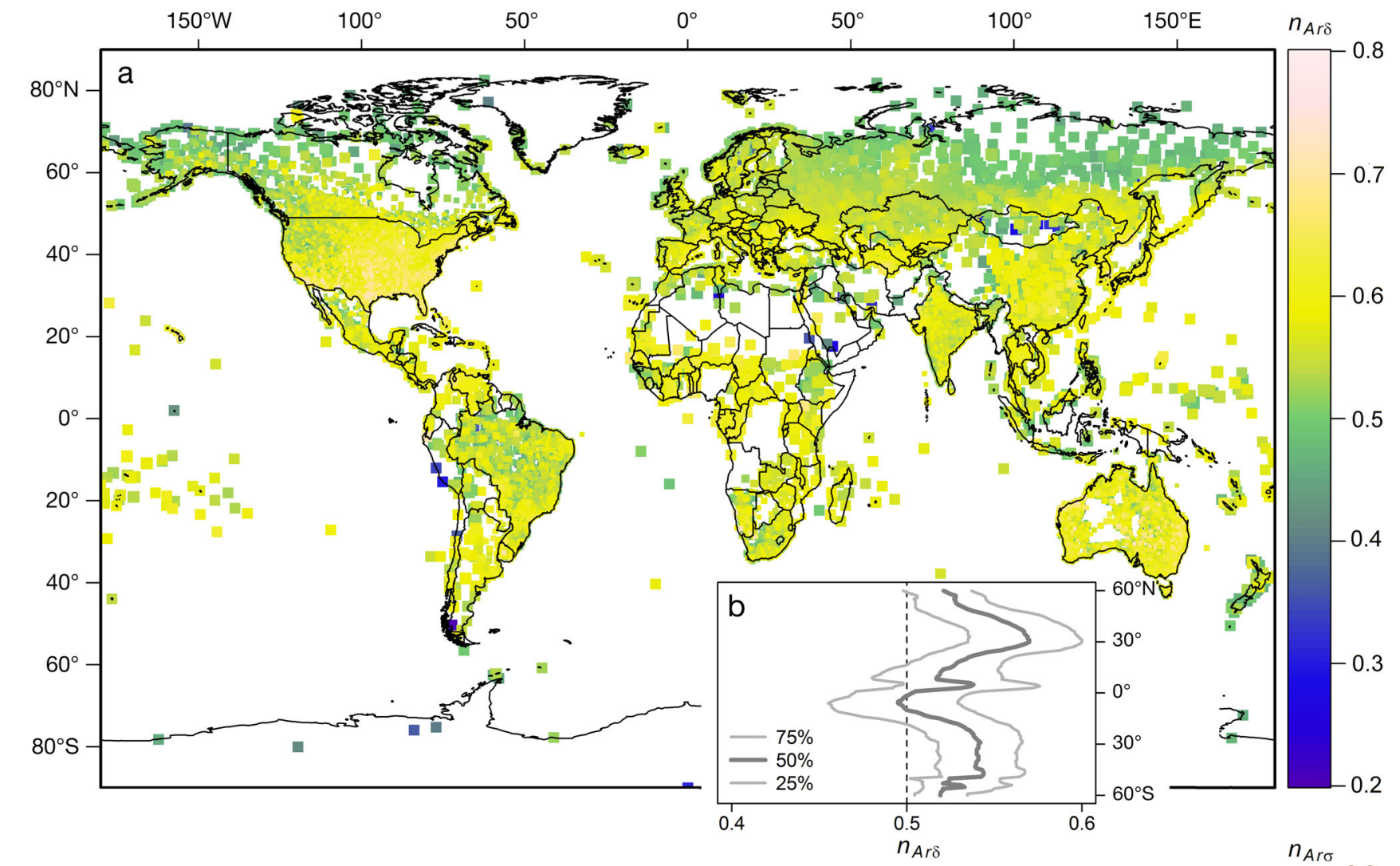

$n_{\text {Aro }}$

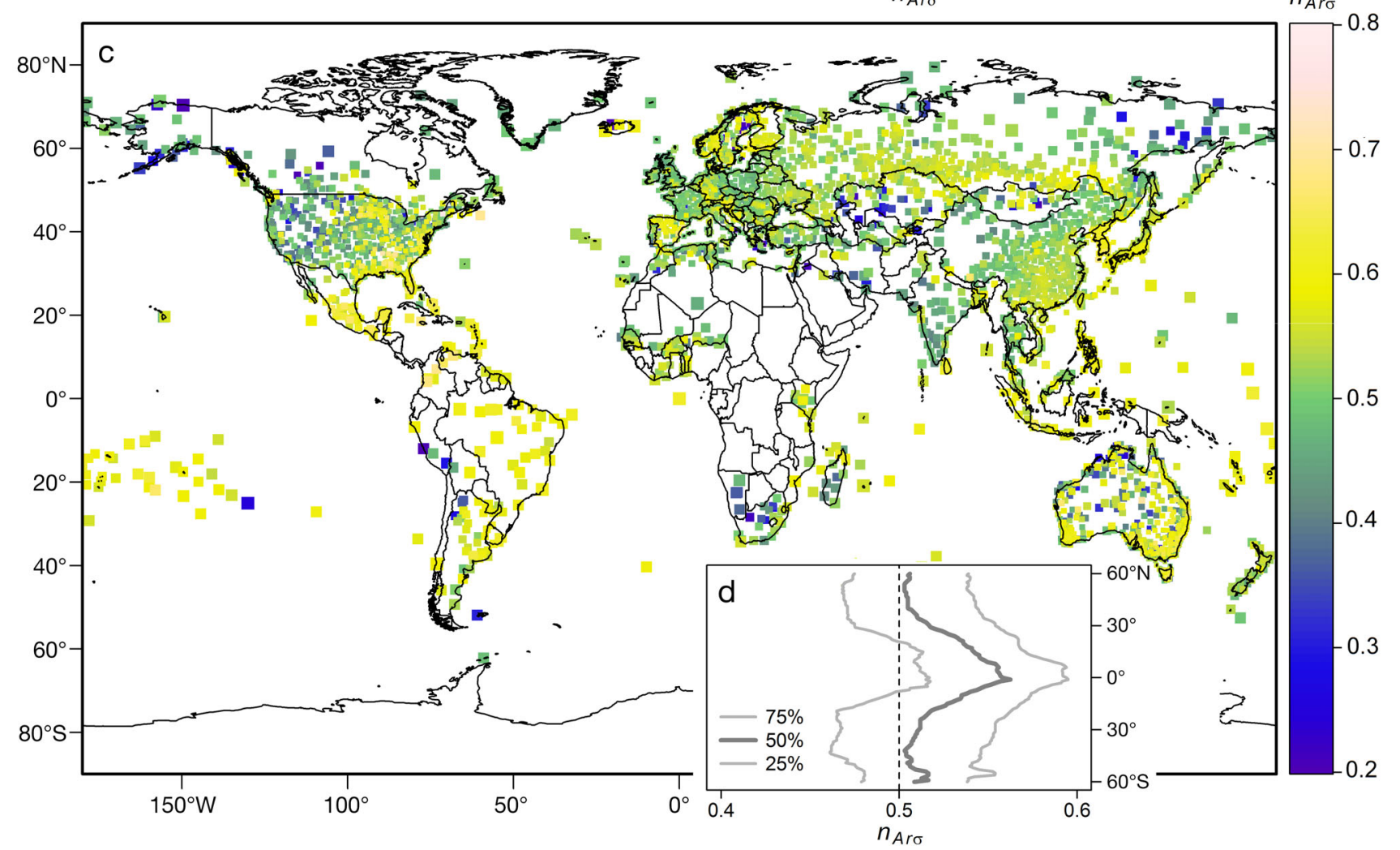

Fig. 4. (a) Spatial distribution of daily $n$ (i.e. $n_{\mathrm{As \delta}}$ ). (b) Latitudinal profile of daily $n$, according to the 25th, 50th and 75 th percentiles. (c) Spatial distribution of sub-daily $n$ (i.e. $n_{\text {Aso }}$ ). (d) Latitudinal profile of sub-daily $n$, according to the 25 th, 50 th and 75 th percentiles (from left to right). The dashed line at 0.5 marks the theoretical threshold for the regular/irregular rainfall 


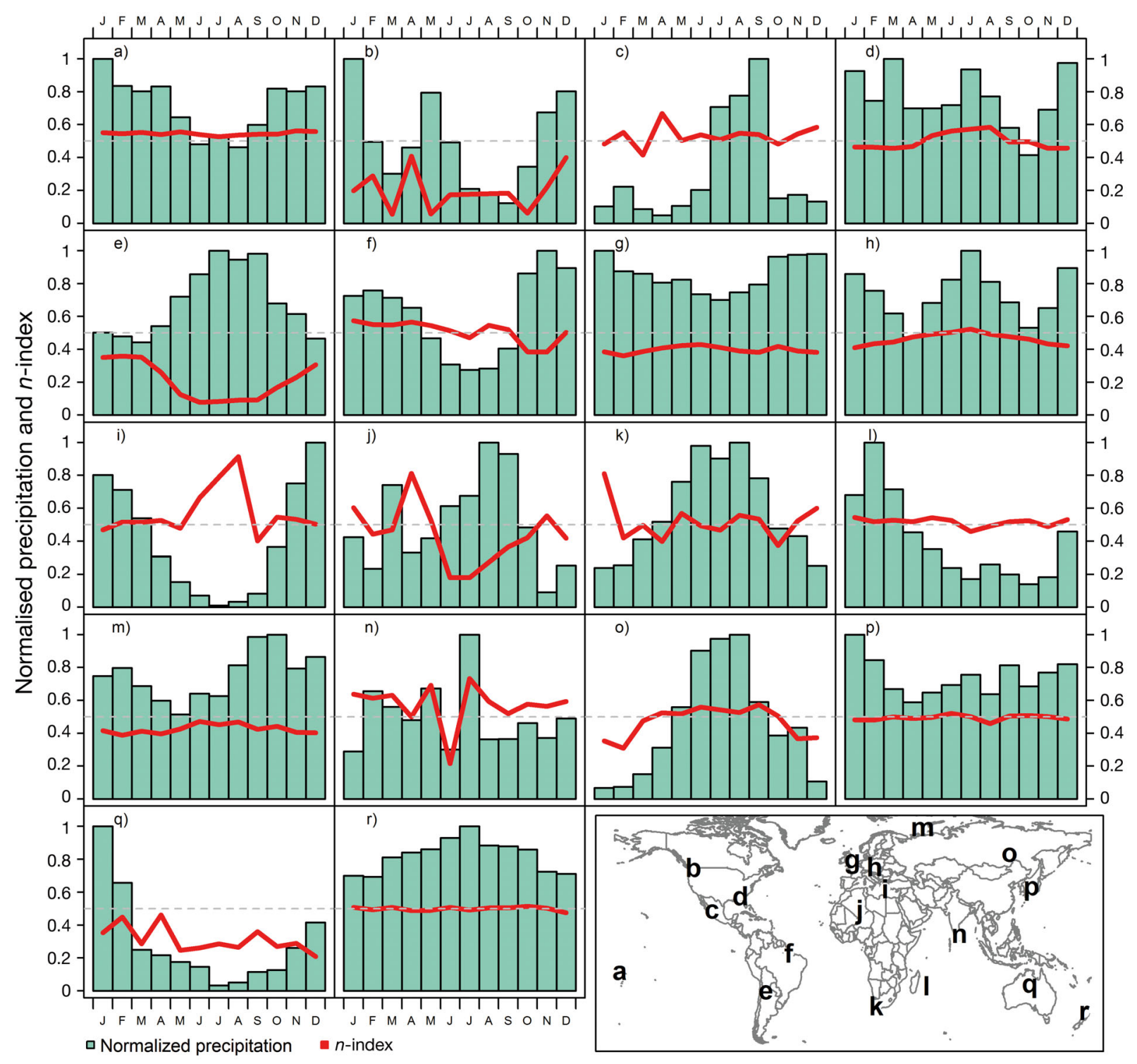

Fig. 5. Monthly averages of sub-daily $n$-index (red lines) and rainfall normalised using the wettest month (bars) for 18 observatories: (a) Hihifo (Wallis Island), (b) Princeton Aerodrome (Canada), (c) Colonia Juan Carras (Mexico), (d) Columbus Metropolitan Airport (Georgia, USA), (e) Salta airport (Argentina), (f) Belem airport (Brazil), (g) London/Heathrow airport (UK), (h) Ústí nad Orlicí (Czech Republic), (i) Milos (Greece), (j) Tamanrasset (Algeria), (k) Cape Columbine (South Africa), (l) SaintDenis/Gillot (La Réunion), (m) Malye Karmakuly (Russia), (n) Vavuniya (Sri Lanka), (o) Chara Airport (Russia), (p) Toyooka (Japan), (q) Territory Grape Farm (Australia), (r) Auckland Aero Aws (New Zealand)

the profile of daily $n$ (Fig. $4 \mathrm{~b}$ ) bears some similarity to the profile of stratiform/convective rain based on the Tropical Rainfall Measuring Mission (Schumacher \& Houze 2003). The differences in the dynamic phenomena at several time scales are strongly related to the effects of time resolution on the $n$-index (see Section 4.5).

Another advantage of sub-daily $n$ is that it presents a suitable seasonal behaviour regarding the annual cycle of each region (Fig. 5). For example, Oceanic climates (Cfb and Cfa according to Köppen classification) generally present a very regular rainfall, which corresponds to $n<0.5$ throughout the year (Fig. 5b,g), although it is close to 0.5 for some regions (Fig. 5a,r). In contrast, Mediterranean climates (Csa and $\mathrm{Csb}$ ) show a higher $n$ in their dry summers $(n>$ $0.6)$, which are characterised by weak thunderstorms (e.g. Fig. 5i). Meanwhile, tropical and humid subtropical climates oscillate around $n=0.5$ throughout the year (Fig. 5d,f,l,p). 


\subsection{Interpretation and uses of the $n$-index}

The $n$-index informs on the behaviour of rainfall over time, i.e. the accumulation of precipitation in relation to the temporal structure (evolution/motion) of a cloud or a cloud system. Generally, the evolution of convective clouds is faster than a frontal system or orographic precipitation. However, convective precipitation may remain stationary in a location for several reasons: constant storm feeding, topographic features, balancing driving forces, etc. In such cases, a value of $n<0.5$ is expected despite the convective character. In fact, a moist air stream is required to maintain the life of a storm, which is reflected in the low $n$-value.

Characterisation of rainfall using $n$ can be used to extrapolate or interpolate the behaviour within a particular rainfall event. For example, torrential rain is usually defined with a threshold (e.g. $60 \mathrm{~mm}$ ) for a particular duration (e.g. 1 h) (Llasat 2001). Using $n_{\text {, }}$ each threshold can be generalised for any event duration (Eq. 2). In addition, from a set of pairs of values (times and amounts), it is possible to estimate amounts for middle time points. This property can be useful for forensic meteorology.

According to fractal analysis of rainfall duration, $n$ can be interpreted as a fractal dimension of the rain rate (see Appendix 2). In fact, analysing the correlation between the fractal type $\left(n_{\mathrm{F}}\right)$ and the absolute $n$ index resulted in a Pearson correlation coefficient of about 0.90. Moreover, the index also showed a certain self-similarity at several time scales. In particular, the comparison between nested and absolute $n$ (Fig. 3a) showed that nested $n$ is a good approximation of absolute $n$. This means that most MAIs are naturally nested (encompassing each other); in other words, maximum precipitation of duration $t_{1}<t_{2}$ generally occurs during the maximum precipitation of duration $t_{2}$. This general phenomenon of nesting is consistent with the results of other research. For example, Olsson et al. (1992) found a scale-invariant behaviour of the rainfall time structure using a boxcounting method in a rainfall time series, which analyses persistence. In another study, Moncho et al. (2011) observed that virtually all global extreme precipitation records are nested within those of longer duration. This is possible for all time scales because the precipitation events present an efficient regimen, and thus, satisfy $n_{\mathrm{As} \delta} \approx n_{\mathrm{As \sigma}} \approx 0.5$. In fact, this critical value is called 'efficient' because it provides the most adequate time structure (temporal irregularity) to describe global extreme precipitation for all time scales (Moncho et al. 2011). In fact, the wettest re- gions of the world usually present an average $n$ index close to 0.5 that is constant throughout the year (e.g. see Fig. 5l,p).

The scale-invariance reflected by the index suggests that it could be useful to perform a disaggregation of precipitation data, or daily-to-sub-daily scaling (e.g. applying to numerical weather or climate models). That is, the behaviour of rainfall accumulation can be transferred, for example, from the daily to the hourly scale. However, additional information is required for this purpose, such as the duration of the event and the number of subevents.

\subsection{Duration and intensity effects on the $n$-index}

Usually, convective phenomena have a shorter duration than frontal systems and large-scale advections. Therefore, it is expected that $n$ for the shortest sub-events is significantly greater than $n$ for the longest sub-events (see Section 3.2).

The results relating to the main sub-events show that the dependence of $n$ on sub-event duration is statistically significant for $>4 \mathrm{~d}$ (Fig. 6a), with a slope of around $-0.0125 \pm 0.0005 \mathrm{~d}^{-1}$. However, the dependence is not remarkable for shorter durations because one can find both convective and stratiform rain of short duration. Initially, the average value is close to 0.5 (efficient regimes). For durations $>4 \mathrm{~d}$, the time slope of $n$ is stronger $\left(-2.5 \pm 0.1 \% \mathrm{~d}^{-1}\right)$, because it is difficult to find many longer lasting convective processes. For durations $>15 \mathrm{~d}, n$ approaches 0.3 (usually associated with stratiform regimes).

On the other hand, the climatic average of the $n$-index is generally independent of the reference intensity (Fig. 6b). However, some features were found for the highest resolution (hourly data) as well as for the highest amounts of precipitation. At an hourly scale, the highest intensity presents an average $n$ of slightly over 0.5 (which is the general average), while at a lower time resolution, the differences are not significant. The accumulation of precipitation depends on the efficiency of the physical phenomenon that produces it. This is particularly visible for rainfall greater than the 95th percentile (calculated for each rain gauge). The places with lower maximum intensity have a greater $n$ (i.e. have convective regimes for their extreme rainfall), while those with the highest intensities in the world have an $n$-index very close to 0.5 (efficient regime). Therefore, the $n$-index of a certain place may depend on the frequency (return period) of rainfall intensities or amounts. 
a

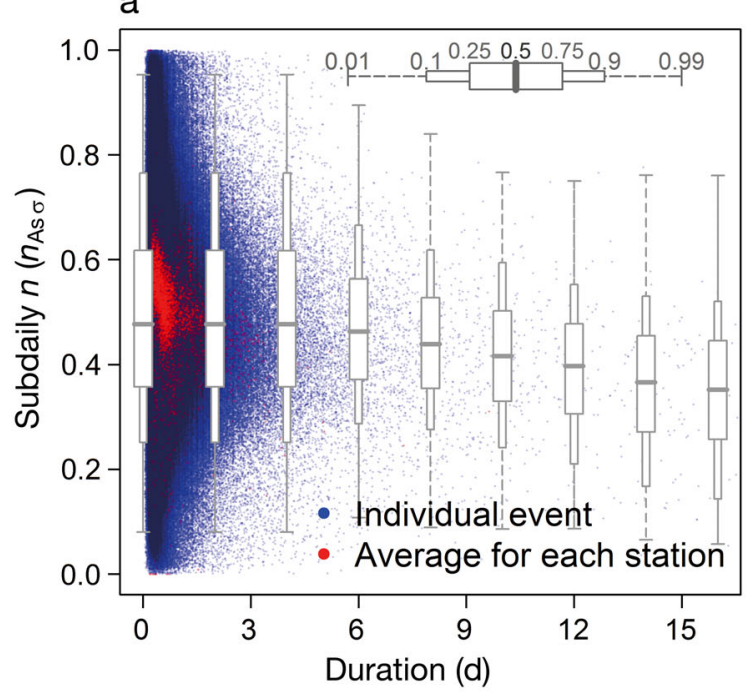

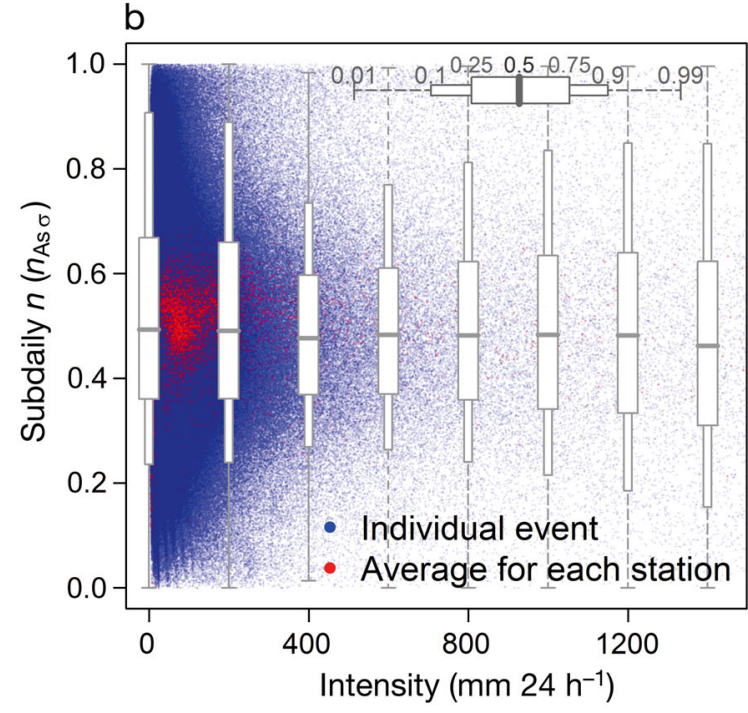

Fig. 6. (a) Dependence of sub-daily $n$ on event duration. (b) Dependence of sub-daily $n$ on reference intensity (from Eq. 2). Box plots represent the relative distribution of points along the domain of $n$. The horizontal boxplot provides a description of the vertical plots (numbers in the former are quantiles)

\subsection{Time resolution effects on the $n$-index}

No general time-dependence of $n$ was found within short events/sub-events (i.e. within a 4 d event, $n$ can vary - or not - and in any way). However, the statistical differences between daily and sub-daily $n$ (see Section 4.2) suggest a time effect on the $n$-index, at least due to the temporal resolution of data. In this sense, a weak but significant relationship was found between the sub-daily $n$ and the time resolution. For a range between 1 and $12 \mathrm{~h}$ resolution at least, average $n$ is given by:

$$
n(r)=0.460(6)+0.028(3) \cdot \ln \frac{r}{r_{o}}
$$

where $n(r)$ is the average $n$ at a time resolution $r$, expressed in hours (i.e. from 1 to $12 \mathrm{~h}$ ), $r_{o}$ is the minimum resolution $(1 \mathrm{~h})$, and the parameter errors in parentheses (significant figure) are at the 95\% confidence level. For example, the average for hourly reports is $n=0.46$, while $n=0.55$ is expected for 24 hourly reporting, i.e. the same value observed for daily $n$ (particularly $n_{\mathrm{As} \delta} \approx 0.54 \pm$ 0.06, according to Section 4.2). Therefore, the regularity of precipitation depends on the time resolution of the measurement, as does persistence, which has been analysed by other authors (Feder 1988, Olsson et al. 1992, Taouti \& Chettih 2014). Taken to extremes, it can be observed that rainfall intensities are more regular (within an event) from $1 \mathrm{~s}$ to another than from $1 \mathrm{~d}$ to another; this phenomenon is independent of the type of precipitation. Using a mathematical view, time resolution effects on the $n$-index can be interpreted as an interference with the fractal duration of the rainfall. That is, atmospheric general circulation shows a self-similarity at several time scales, and it is mathematically reflected in the differences between the daily and sub-daily $n$-index.

In summary, time resolution may affect the measurement of MAI; and thus, Eq. (1) can be modified as:

$$
\ln \frac{I\left(t_{1} r\right)}{I\left(t_{o}, r_{o}\right)}=\left[n+\alpha \cdot \ln \left(\frac{r}{r_{o}}\right)\right] \ln \left(\frac{t_{o}}{t}\right)
$$

where $I(t, r)$ and $I\left(t_{o}, r_{o}\right)$ are MAI that respectively correspond to a time $t$ with a resolution $r$, and a time $t_{o}$ with a resolution $r_{o}, \alpha$ is the new parameter (which is close to 0.028 according to Eq. 4) and $n$ is the corrected index according to time resolution. Hence, sub-daily and daily $n$ were calculated again using Eq. (5) for analysis without the effect of temporal resolution. After the correction, the indexes were very similar to each other, so much so that new corrected distributions could be combined, showing a better spatial coherence (Fig. 7) than before correction. For example, note the spatial incoherence between Spain and France in the index field of Fig. 4c, which is lower in Fig. $7 \mathrm{~b}$.

With this modification of $n$, the analysis of the rainfall time structure is similar to that in Section 4.2, especially according to sub-daily $n$. The main regions with a high irregularity (within a rainfall event) are the Gulf of Mexico, the Caribbean Sea and some parts of Oceania. Rainforests and most of the grasslands of the world have a sub-daily $n$ close to 0.5 . The coldest areas have a low variability $(n<0.5)$, as do the regions with predominant maritime winds. 


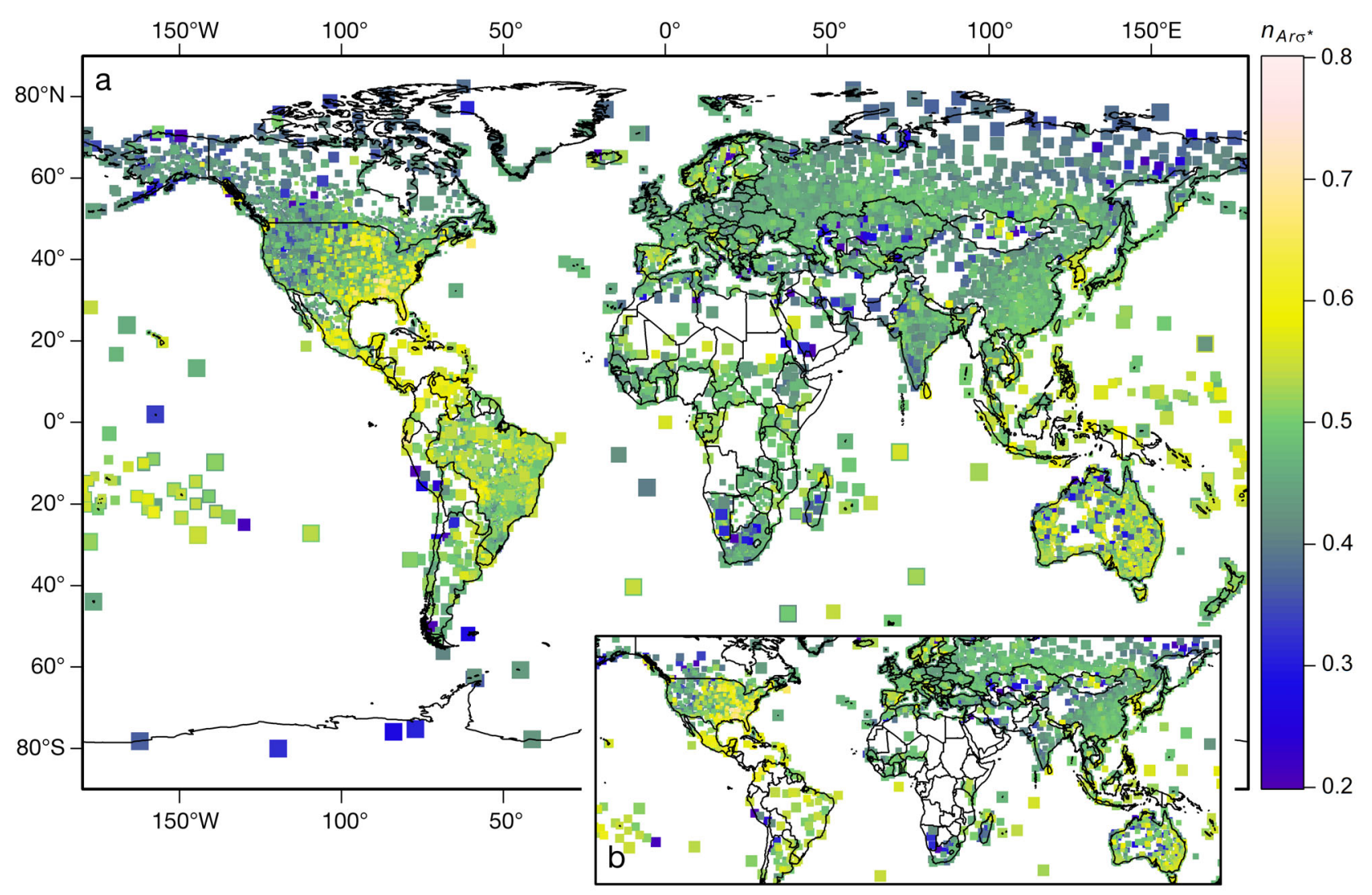

Fig. 7. (a) Final combination of sub-daily and daily $n$ (first overlaid onto second), both corrected using the relationship with the time resolution (Eq. 5) and processed for $1 \mathrm{~h}$ resolution. (b) A sample of the corrected sub-daily $n$, processed for $1 \mathrm{~h}$ resolution

\section{CONCLUSIONS AND PERSPECTIVES}

The $n$-index for particular rainfall events is bounded between 0 and 1 , but its average value is between 0.4 and 0.6 for most cases, i.e. it has a small climatic range. However, the threshold of 0.5 allows discrimination between areas with a predominance of regular rainfall $(n<0.5)$ and irregular rainfall $(n>$ 0.5 ), in the sense of the concentration or time distribution of the precipitation intensities (within an event). Since there is a link between the time structure of rainfall and its causal processes (advection/ convection), the value of $n$ gives an indication of the predominance of stratiform/convective rain.

The method of calculating the maximum average intensities does not affect the $n$-index; differences between absolute and nested $n$ are $<1 \%$. This indicates that precipitation generally has a nested time structure. Therefore, self-similarity is found at several time scales, so that each maximum accumulation of shorter duration is included within longer ones. In fact, $n$ can be interpreted as a fractal dimension of the maximum average intensities, strongly related to the box-counting dimension of rainfall duration.

Nevertheless, estimation of $n$ shows an uncertainty of up to $30 \%$ due to the use of a daily or sub-daily resolution, and up to $50 \%$ if dry pauses are considered as part of the rainfall event rather than using its strict duration. From this analysis, we conclude that a sub-daily scale and an absolutely strict duration should be recommended for calculating $n$.

In agreement with the sub-daily/daily atmospheric patterns, the results showed that $n$ is usually greater at the daily scale than at the sub-daily scale for regular rainfall $(n<0.5)$, while for irregular precipitation $(n>0.5), n$ at the daily scale is similar to or even less than that at a sub-daily scale. This is because stratiform precipitation is more regular at a sub-daily scale than a daily scale, while the convection processes are similarly irregular at both scales.

Regarding the dependencies of $n$, it is approximately constant relative to time and intensity (within a particular rain event), but depends weakly on the temporal resolution of the data and on the frequency of the event. A higher $n$ is expected for rarer events, 
while the average $n$-index is lower for higher temporal resolutions, which reflect better the processes of convection/advection.

Finally, some conclusions about spatial distribution of the $n$-index can be made. The areas with less irregularity $(n<0.5)$ are the colder regions (polar and high mountain areas) and the orographic retention zones, or those with quite remarkable maritime advections. The highest irregularities in rainfall time structure $(n>0.5)$ are found near the warmest seas (especially the Gulf of Mexico and the Caribbean Sea). The rainforests and most grasslands of the world have an $n$-index close to 0.5 .

All these findings should be treated with caution due to the limited data, and these data do not equally cover all regions of the earth. However, some important insights can be drawn from this study. Connections between the irregularity of precipitation (nindex) and the nature of its formation (advective/ convective) are supported by the coincidence in the spatial and temporal distributions of convective rain and $n$. These connections should be explored in future work, especially using information from numerical weather models concerning the convective rainfall fraction, and comparisons with more accurate observations at sub-daily scales.

Finally, characterising rainfall using $n$ can allow the extrapolation/interpolation of the behaviour of the rain rate for several time intervals. This is useful for now-casting and forensic meteorology. That is, the $n$-index can be a new tool for temporal downscaling or disaggregation of several rainfall types (stratiform, convective or mixed).

Acknowledgements. This work would not be possible without the contribution of the Global Historical Climatology Network-Daily database (GHCN-Daily) and the Integrated Surface Hourly-Integrated Surface Data (ISH/ISD) of the National Climatic Data Centre (NCDC).

\section{LITERATURE CITED}

Benhamrouche A, Boucherf D, Hamadache R, Bendahmane L, Martin-Vide J, Teixeira Nery J (2015) Spatial distribution of the daily precipitation concentration index in Algeria. Nat Hazards Earth Syst Sci 15:617-625

Berne A, Delrieu G, Boudevillain B (2009) Variability of the spatial structure of intense Mediterranean precipitation. Adv Water Resour 32:1031-1042

Beven KJ (2012) Rainfall-runoff modelling: the primer. Wiley-Blackwell, Oxford

Casas MC, Rodríguez R, Redaño Á (2010) Analysis of extreme rainfall in Barcelona using a microscale rain gauge network. Meteorol Appl 17:117-123

Chow VT, Maidment DR, Mays LW (1988) Applied hydrology. McGraw-Hill Series in Water Resources and Envi- ronmental Engineering. McGraw-Hill, New York, NY

Christian HJ, Blakeslee RJ, Boccippio DJ, Boeck WL and others (2003) Global frequency and distribution of lightning as observed from space by the Optical Transient Detector. J Geophys Res 108:4005, doi:10.1029/2002JD 002347

Cortesi N, Gonzalez-Hidalgo JC, Brunetti M, Martin-Vide J (2012) Daily precipitation concentration across Europe 1971-2010. Nat Hazards Earth Syst Sci 12:2799-2810

> Cowpertwait PSP, Isham V, Onof C (2007) Point process models of rainfall: developments for fine-scale structure. Proc R Soc A 463:2569-2587

D'Odorico P (2005) Potential for landsliding: dependence on hyetograph characteristics. J Geophys Res 110:F01007, doi:10.1029/2004JF000127

Dennis JE, Schnabel RB (1983) Numerical methods for unconstrained optimization and nonlinear equations. Prentice-Hall, Englewood Cliffs, NJ

Dunn RJH, Willett KM, Thorne PW, Woolley EV and others (2012) HadISD: a quality controlled global synoptic report database for selected variables at long-term stations from 1973-2011. Clim Past 8:1649-1679

Falconer K (ed) (2003) Mathematical background. In: Fractal geometry: mathematical foundations and applications. John Wiley \& Sons, Chichester, p 3-26

Feder J (1988) Fractals. Plenum Press, New York, NY

$>$ Gadgil S (2003) The Indian monsoon and its variability. Annu Rev Earth Planet Sci 31:429-467

Ghahraman B, Hosseini SM (2005) A new investigation on the performance of rainfall IDF models. Iran J Sci Technol B 29:333-342

Granger OE (2005) Precipitation distribution. In: Oliver JE (ed) Encyclopedia of world climatology. Encyclopedia of Earth Sciences Series, Springer, Dordrecht, p 576-583

> Gupta VK, Waymire EC (1993) A statistical analysis of mesoscale rainfall as a random cascade. J Appl Meteorol Climatol 32:251-267

Jiangnan L, Yanping Z, Fangzhou L, Feiyun G, Weibiao L (2014) The structural characteristics of precipitation in Asian-Pacific's three monsoon regions measured by tropical rainfall measurement mission. Acta Oceanol Sin 33: 111-117

Klein-Tank AMG, Können GP (2003) Trends in indices of daily temperature and precipitation extremes in Europe 1946-99. J Clim 16:3665-3680

Koutsoyiannis D (1993) A scaling model of a storm hyetograph. Water Resour Res 29:2345-2361

Koutsoyiannis D, Onof C, Wheater HS (2003) Multivariate rainfall disaggregation at a fine timescale. Water Resour Res 39:1173-1191

Liu XC, Gao TC, Liu L (2013) A comparison of rainfall measurements from multiple instruments. Atmos Meas Tech 6:1585-1595

Llasat MC (2001) An objective classification of rainfall events on the basis of their convective features: application to rainfall intensity in the north-east of Spain. Int J Climatol 21:1385-1400

> Llasat MC, Puigcerver M (1997) Total rainfall and convective rainfall in Catalonia, Spain. Int J Climatol 17:1683-1695

> Maraun D, Osborn TJ, Gillett NP (2008) United Kingdom daily precipitation intensity: improved early data, error estimates and an update from 2000 to 2006. Int J Climatol 28:833-842

Martín-Vide J (2004) Spatial distribution of a daily precipitation concentration index in peninsular Spain. Int J Clima- 
tol 24:959-971

Mehrotra R, Westra S, Sharma A, Srikanthan R (2012) Continuous rainfall simulation. 2. A regionalized daily rainfall generation approach. Water Resour Res 48:W01536, doi:10.1029/2011WR010490

Menne MJ, Durre I, Vose RS, Gleason BE, Houston TG (2012) An overview of the Global Historical Climatology Network-Daily database. J Atmos Ocean Tech 290 897-910. Data: ftp://ftp.ncdc.noaa.gov/pub/data/ghcn/ daily/ (accessed on 25 July 2015)

Moncho R, Belda F, Caselles V (2009) Climatic study of the exponent ' $\mathrm{n}$ ' in IDF curves: application for the Iberian Peninsula. Tethys 6:3-14

Moncho R, Belda F, Caselles V (2011) Distribución probabilística de los extremos globales de precipitación. Nimbus 27-28:119-135

Monjo R, Pórtoles J, Ribalaygua J (2013) Detection of inhomogeneities in daily data: a test based in the Kolmogorov-Smirnov goodness-of-fit test. 9th Data Management Workshop of EUMETNET, El Escorial (Madrid), 6-8 November 2013, p 38-39

Muenchen RA, Hilbe JM (2010) R for Stata users. Statistics and computing. Springer, New York, NY

Olsson J, Niemczynowicz J, Berndtsson R, Larson M (1992) An analysis of the rainfall time structure by box counting - some practical implications. J Hydrol (Amst) 137: 261-277
R Development Core Team (2010) R: a language and environment for statistical computing. R Foundation for Statistical Computing, Vienna, www.R-project.org

Schertzer D, Lovejoy S (1987) Physical modelling and analysis of rain and clouds by anisotropic scaling multiplicative processes. J Geophys Res 92:9693-9714

Schumacher C, Houze RA Jr (2003) Stratiform rain in the tropics as seen by the TRMM Precipitation Radar. J Clim 16:1739-1756

Singh P, Nakamura K (2010) Diurnal variation in summer monsoon precipitation during active and break periods over central India and southern Himalayan foothills. J Geophys Res 115:D12122, doi:10.1029/2009JD012794

Smith A, Lott N, Vose R (2011) The Integrated Surface Database: recent developments and partnerships. Bull Am Meteorol Soc 92:704-708. Data: ftp://ftp.ncdc.noaa.gov/ pub/data/noaa/ (accessed on 25 July 2015)

Taouti MB, Chettih M (2014) Fractal and multifractal analyses of the temporal structure of daily rainfall in a Mediterranean climate in northern Algeria. Tethys 11:3-12

Watt E, Marsalekb J (2013) Critical review of the evolution of the design storm event concept. Can J Civ Eng 40: 105-113

Westra S, Mehrotra R, Sharma A, Srikanthan R (2012) Continuous rainfall simulation. 1. A regionalized subdaily disaggregation approach. Water Resour Res 48:W01535, doi:10.1029/2011WR010489

Appendix 1. Obtaining Eq. (2)

Eq. (2) was obtained by Moncho et al. (2009) using the relationship between the life cycle of a rainfall system and its expected average intensity (physical reasoning). In this appendix, the first author (R. Moncho/Monjo) shows an alternative method to obtain the equation.

By definition of maximum average intensity (MAI), maximum accumulation can be written as:

$$
I(t) \cdot t=P(t)
$$

where $I(t)$ is the MAI of a time $t$ and $P(\mathrm{t})$ is the maximum accumulation in this time. Thus, the time derivative $\left({ }^{\prime}\right)$ of both is given by:

$$
I^{\prime}(t) \cdot t+I(t)=P^{\prime}(t)
$$

Since the maximum accumulation $P(t)$ increases with time, $P^{\prime}(t) \geq 0$, we have:

$$
I^{\prime}(t) \cdot t+I(t) \geq 0
$$

Isolating the term of the derivative, if $t>0$ we obtain:

$$
I^{\prime}(t) \geq-\frac{I(t)}{t}
$$

Since the MAI decreases with time, $I^{\prime}(t) \leq 0$, the inequality is completed as:

$$
-\frac{I(t)}{t} \leq I^{\prime}(t) \leq 0
$$

That is, the time derivative of MAI is bounded between 0 and $-I(t) / t$. Obviously, the solution to this inequality is not unique. Solutions can be found taking the derivative $I^{\prime}(t) \equiv$ $I^{\prime}(t, n)$ as a function of a parameter $n$ bounded between 0 and 1 , such as $I^{\prime}(t, 0)=0, I^{\prime}(t, 1)=-I(t) / t$ and $-I(t) / t<I^{\prime}(t, n)<0$ for $0<n<1$. The simplest function $I^{\prime}(t, n)$ that satisfies all these conditions is the linear case:

$$
I^{\prime}(t, n) \approx-n \frac{I(t)}{t}
$$

Operating as follows:

$$
\frac{1}{I(t)} \mathrm{d} I(t)=-\frac{n}{t} \mathrm{~d} t
$$

and integrating gives:

$$
\ln I(t)=-n \ln t+\ln k
$$

where $k$ is a constant of integration. The MAI curve becomes:

$$
I(t)=k \cdot t^{-n}
$$

To express the curve without displaying the constant $k$, it is possible to divide $I(\mathrm{t})$ and $I\left(t_{0}\right)$, so that:

$$
\frac{I(t)}{I\left(t_{o}\right)}=\left(\frac{t_{o}}{t}\right)^{n}
$$


Appendix 2. Relationship between the $n$-index and the fractal dimension

\section{A2.1. Fractal dimension}

The familiar ideas of perimeter, area and volume were generalised by the Hausdorff measures using the notion of fractional or fractal dimensions (Falconer 2003). A $d$-dimensional volume $(v)$ can be defined as a spatial measure with fractal dimension $d$ (Feder 1988, Falconer 2003):

$$
v=k \cdot L^{d}
$$

where $L$ is the spatial resolution and $k$ is a constant. Given a fractal volume $v$, the average density $\rho$ of a known variable $x$ with respect to this volume is defined as:

$$
\rho=\frac{X}{V}=\frac{X}{k \cdot L^{d}}
$$

For example, the number of buildings along a coastline is a known variable, but its density depends on the spatial resolution of measurement of coastline length.

In this sense, precipitation accumulation is also a well known variable, but its temporal concentration depends on the time resolution. Therefore, rainfall duration can be considered as a fractal time, similar to the fractal perimeter of a coastline. Continuing the parallel with the spatial density of the number of buildings, rainfall intensity can be defined as the temporary density of the number of bucket-tips counted by an automatic rain gauge, or of the millimetres recorded in a manual rain gauge.

\section{A2.2. Fractal duration of rainfall}

The fractal duration of rainfall can be measured using the box-counting dimension, also known as the MinkowskiBouligand dimension, which is closely related to the Hausdorff-Besicovitch dimension (Falconer 2003). This method consists of regrouping a time series into non-overlapping segments (boxes) of ever larger size $(r)$, i.e. with lower time resolution. The number $N_{r}$ of non-overlapping intervals (of size $r$ ) with positive counts satisfies the power-law relation (Olsson et al. 1992, Taouti \& Chettih 2014):

$$
N_{r}=C \cdot r^{d-1}
$$

where $C$ is a constant and $d$ is the fractal dimension, which is
$<1$ for the case of rainfall duration. With this, the fractal duration $D_{r}$ of a time series is a $d$-volume obtained by multiplying the time resolution or fragment size $r$ by the number $N_{r}$, according to:

$$
D_{r} \equiv r \cdot N_{r}=C \cdot r^{d}
$$

where the time resolution $r$ is taken as a natural number (without units) corresponding to the number of days, and thereby, the constant $C$ has the same units as $D_{r}$, which is expressed as a ratio (i.e. wet days per total days). Note the fractal duration of rainfall is bounded between the instantaneous case $(d=1)$ and the permanent case $(d=0)$. The definition of the fractal duration can be better understood by referring to the example in Table A1.

\section{A2.3. MAI}

Both maximum and total averaged intensity of a rainfall event depend on the time resolution, mainly because its duration has a fractal dimension. An individual rainfall event can be defined as a set of $N_{r}$ consecutive or nonconsecutive reports of non-zero values of rainfall at a time resolution $r$, with possible pauses of less than a fixed time interval (e.g. $1 \mathrm{~d}$ or $r$ ). The averaged intensity $a_{r}$ of this event is the ratio between its precipitation amount $p$ and its total duration $D_{r}=N_{r} r$ :

$$
a_{r} \equiv \frac{p}{D_{r}}
$$

If time resolution is modified to $r_{1}<r_{\text {, the ratio between }}$ the initial intensity $a_{r}$ and the modified intensity $a_{1}$ is:

$$
\frac{a_{r}}{a_{1}}=\frac{D_{1}}{D_{r}}=\left(\frac{r_{1}}{r}\right)^{d}
$$

where $d$ is the fractal dimension of the event duration, according to Eq. (A14). If total duration $D_{r}=r$, it is expected that $r_{1} \leq D_{1} \leq r$. Applying Eq. (A15), the maximum amounts corresponding to time resolutions $r$ and $r_{1}$, respectively, are $P_{r}=a_{r} r$ and $a_{1} r_{1} \leq P_{1} \leq a_{r} r$. Dividing this last inequality by $P_{r}$ gives:

$$
\frac{a_{1} r_{1}}{a_{r} r} \leq \frac{P_{1}}{P_{r}} \leq 1
$$

\begin{tabular}{|c|c|c|c|c|c|c|c|c|c|c|c|c|c|c|c|c|}
\hline $\boldsymbol{r}$ & \multicolumn{16}{|c|}{$\boldsymbol{p}_{\boldsymbol{j}, \boldsymbol{r}}$} \\
\hline 1 & 1 & 3 & 5 & 3 & 0 & 0 & 0 & 2 & 0 & 0 & 0 & 0 & 0 & 0 & 0 & 1 \\
\hline 2 & \multicolumn{2}{|c|}{4} & \multicolumn{2}{|c|}{8} & \multicolumn{2}{|c|}{0} & \multicolumn{2}{|c|}{2} & & & \multicolumn{2}{|c|}{0} & \multicolumn{2}{|c|}{0} & \multicolumn{2}{|c|}{1} \\
\hline 4 & \multicolumn{4}{|c|}{12} & \multicolumn{4}{|c|}{2} & \multicolumn{4}{|c|}{0} & \multicolumn{4}{|c|}{1} \\
\hline 8 & \multicolumn{8}{|c|}{14} & \multicolumn{8}{|c|}{1} \\
\hline 16 & \multicolumn{16}{|c|}{15} \\
\hline
\end{tabular}

Defining maximum average intensities $I_{1}$ and $I_{r}$ of time reso-

Table A1. Example of a $16 \mathrm{~h}$ rainfall event, with 2 'dry' pauses of $<24 \mathrm{~h}$. Precipitation amounts $p_{j, r}(\mathrm{~mm})$ depend on the time resolution $r(\mathrm{~h})$. The other stated quantities are the number of positive counts $N_{r}$ (Eq. A13), the fractal duration $D_{r}$ (Eq. A14) expressed as a ratio, the averaged intensity $a_{r}$ (Eq. A15) in $\mathrm{mm} \mathrm{h}^{-1}$, and the maximum average intensity $I_{r}$ (Eq. A18) in mm $\mathrm{h}^{-1}$

\begin{tabular}{ccccc}
$\boldsymbol{N}_{\boldsymbol{r}}$ & $\boldsymbol{r} \boldsymbol{N}_{\boldsymbol{r}}$ & $\boldsymbol{D}_{\boldsymbol{r}}$ & $\boldsymbol{a}_{\boldsymbol{r}}$ & $\boldsymbol{I}_{\boldsymbol{r}}$ \\
\hline 6 & 6 & 0.38 & 2.50 & 5 \\
4 & 8 & 0.5 & 1.88 & 4 \\
3 & 12 & 0.75 & 1.25 & 3 \\
2 & 16 & 1 & 0.94 & 1.75 \\
1 & 16 & 1 & 0.94 & 0.94
\end{tabular}


lutions $r_{1}$ and $r$ as $I_{1} \equiv P_{1} / r_{1}$ and $I_{r} \equiv P_{r} / r=a_{r}$ :

$$
\frac{a_{1}}{a_{r}} \leq \frac{I_{1}}{I_{r}} \leq \frac{r}{r_{1}}
$$

That is, the relationship between averaged intensities is given by Eq. (A16), multiplying by the time resolutions:

$$
\left(\frac{r}{r_{1}}\right)^{d} \leq \frac{I_{1}}{I_{r}} \leq \frac{r}{r_{1}}
$$

Taking the logarithm of Eq. (A18) and dividing by $\ln \left(r / r_{1}\right)$, it is possible to obtain:

$$
d \leq n_{F} \leq 1
$$

Editorial responsibility: Eduardo Zorita, Geesthacht, Germany where $n_{\mathrm{F}}$ is defined as $n_{F} \equiv \ln \left(I_{1} / I_{r}\right) / \ln \left(r / r_{1}\right)$, which is bounded between 2 values ( $d$ and 1 ). That is:

$$
\frac{I_{1}}{I_{r}}=\left(\frac{r}{r_{1}}\right)^{n_{F}}
$$

The exponent $n_{F}$ is interpreted as a fractal dimension bounded between 0 and 1, respectively, for a constant intensity (precipitation amount increasing linearly) and for an instantaneous precipitation (point value). That is, the dimension $n_{F}$ of the maximum average intensity is somewhere between a point and a line.

Submitted: July 27, 2015; Accepted: November 24, 2015 Proofs received from author(s): January 19, 2016 